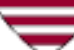

Faculty Research Working Papers Series

\title{
Soldiers Returning from Iraq and Afghanistan: The Long-term Costs of Providing Veterans Medical Care and Disability Benefits
}

\author{
Linda Bilmes \\ John F. Kennedy School of G overnment - Harvard University
}

January 2007

RWP07-001

The views expressed in the K SG Faculty Research Working Paper Series are those of the author(s) and do not necessarily reflect those of the John F. Kennedy School of Govemment or of Harvard University. Faculty Research Working Papers have not undergone formal review and approval. Such papers are included in this series to elicit feedback and to encourage debate on important public policy challenges. Copyright belongs to the author(s). Papers may be downloaded for personal use only. 


\title{
SOLDIERS RETURNING FROM IRAQ AND AFGHANISTAN: The Long-term Costs of Providing Veterans Medical Care and Disability Benefits
}

\author{
Linda Bilmes \\ Kennedy School of Government \\ Harvard University
}

\begin{abstract}
EXECUTIVE SUMMARY:
This paper analyzes the long-term needs of veterans returning from the Iraq and Afghanistan conflicts, and the budgetary and structural consequences of these needs. The paper uses data from government sources, such as the Veterans Benefit Administration Annual Report. The main conclusions of the analysis are that:
\end{abstract}

(a) the Veterans Health Administration (VHA) is already overwhelmed by the volume of returning veterans and the seriousness of their health care needs, and it will not be able to provide a high quality of care in a timely fashion to the large wave of returning war veterans without greater funding and increased capacity in areas such as psychiatric care;

(b) the Veterans Benefits Administration (VBA) is in need of structural reforms in order to deal with the high volume of pending claims; the current claims process is unable to handle even the current volume and completely inadequate to cope with the high demand of returning war veterans; and

(c) the budgetary costs of providing disability compensation benefits and medical care to the veterans from Iraq and Afghanistan over the course of their lives will be from $\$ 350$ $\$ 700$ Billion, depending on the length of deployment of US soldiers, the speed with which they claim disability benefits and the growth rate of benefits and health care inflation.

Key recommendations include: increase staffing and funding for veterans medical care particularly for mental health treatment; expand staffing and funding for the "Vet Centers," and restructure the benefits claim process at the Veterans Benefit Administration.

This paper was prepared for the Allied Social Sciences Association Meetings in Chicago, January, 2007. The views expressed here are solely those of the author and do not represent any of the institutions with which she is affiliated, now or in the past. 


\section{$\underline{\text { Introduction }}$}

The New Year has brought with it the grim fact that 3000 American soldiers have been killed so far in Iraq. A statistic that merits equal attention is the unprecedented number of US soldiers who have been injured. As of September 30, 2006, more than 50,500 US soldiers have suffered non-mortal wounds in Iraq, Afghanistan and nearby staging locations - a ratio of 16 wounded servicemen for every fatality ${ }^{1}$. This is by far the highest killed-to-wounded ratio in US history. For example, in the Vietnam and Korean wars there were 2.6 and 2.8 injuries per fatality, respectively. World Wars I and II had fewer than 2 wounded servicemen per death ${ }^{2}$.

While it is welcome news and a credit to military medicine that more soldiers are surviving grievous wounds, the existence of so many veterans, with such a high level of injuries, is yet another aspect of this war for which the Pentagon and the Administration failed to plan, prepare and budget. There are significant costs and requirements in caring for our wounded veterans, including medical treatment and long-term health care, the payment of disability compensation, pensions and other benefits, reintegration assistance and counseling, and providing the statistical documentation necessary to move veterans seamlessly from the Department of Defense payroll into Department of Veterans Affairs medical care, and to process VA disability claims easily.

To date, 1.4 million US servicemen have been deployed to the Global War on Terror (GWOT), the Pentagon's name for operations in and around Iraq and Afghanistan 3 . The servicemen who have been officially wounded are a small percentage of the veterans who will be using the veteran's administration medical system. Hundreds of thousands of these men and women will be seeking medical care and claiming disability compensation for a wide variety of disabilities that they incurred during their tours of duty ${ }^{4}$. The cost of

\footnotetext{
${ }^{1}$ Department of Veterans Affairs, Office of Public Affairs, “America's Wars”, September 30, 2006. This document shows that the number of non-mortal woundings in the Global War on Terror (combining Iraq, Afghanistan and surrounding duty stations) as of 9/30/06 was 50,508 compared with 2333 deaths in battle plus 707 other deaths in theater. The comparison numbers for previous conflicts are as follows: Desert Storm/Desert Shield: 1.2 wounded per fatality; Vietnam: 2.6 wounded per fatality; Korea: 2.8 wounded per fatality; World War II: 1.6 wounded per fatality; World War I: 1.8 wounded per fatality; Civil War (union): .7 wounded per fatality; War of 1812: .5 wounded per fatality; American Revolution: 7 wounded per fatality. Note: the VA defines non-mortal wounded as those who are "medically evacuated from theatre". The Pentagon has several definitions, but the daily casualty reports on its website use a narrower definition referring to those wounded by shrapnel, bullets, etc. Using this narrow definition, the Iraq conflict has a ratio of 8 wounded per fatality - still much higher than any previous war in US history.

${ }^{2}$ Ibid.

${ }^{3}$ As of September 30, 2006, 1,406,281 unique service members have been deployed to the wars in Iraq and Afghanistan, according to the Department of Defense, Defense Manpower Data Center, and "Contingency Tracking System." The Veterans Health Administration (VHA) Office of Public Health and Environmental Hazards, November 2006 uses the number 1.4 million (as of November 2006). The Veterans Benefits Administration (VBA) lists 1,324,419 unique servicemen deployed to GWOT as of May 2006 (prepared by VBA/OPA\&I, 7/20/06).

${ }^{4}$ Based on an analysis of the first Gulf War in 1991, using the Gulf War Veterans Information System (GWVIS August 2006, chart on "Gulf War Veteran Outpatient Stays)), there were 297,125 veterans from that conflict who used VA medical care, or $48.4 \%$. If the same percentages of Iraq/Afghan veterans use VA medical care then VA should expect approximately 700,000 new patients from the 1.4 million existing
} 
providing such care and paying disability compensation is a significant long-term entitlement cost that the US will be paying for the next forty years ${ }^{5}$.

The objective of this paper is to examine the structural and budgetary requirements for caring for the returning war veterans from Iraq and Afghanistan, in terms of US capacity to pay disability compensation, provide high quality medical care, and provide other essential benefits. The paper grew out of a previous paper that was co-authored in January 2005 with Columbia University professor Joseph Stiglitz, in which the overall costs of the war in Iraq were estimated to exceed $\$ 2$ trillion. One of the long-term costs cited in that paper was the cost associated with providing health care and disability benefits to veterans ${ }^{6}$. This paper expands on that topic.

Unlike the previous paper ${ }^{7}$, this study does not differentiate between veterans returning from Iraq, or Afghanistan or adjacent locations (such as Kuwait, an important staging post for Iraq) in the GWOT, for three reasons. First, nearly one-third of the servicemen involved in the war have been deployed two or more times and many of them have served both in Iraq and Afghanistan, and/or other locations ${ }^{8}$. Second, the data available from the VA does not distinguish between the wars in Iraq and Afghanistan. Third, for the purposes of estimating the long-term costs of taking care of the returning veterans it does not matter where they served. However it is worth noting that the overwhelming majority of the deaths and injuries incurred in the GWOT have been in Iraq. Among those listed as wounded on the Pentagon's casualty reports, more than $95 \%$ have been injured in Iraq $^{9}$.

servicemen. Increasing the number of unique servicemen deployed will increase medical and disability usage.

${ }^{5}$ Veterans' disability pay is an entitlement program, like Medicare and Social Security. Once a veteran has been approved to receive disability pay, he or she is entitled to receive an annual payment and cost-ofliving adjustments. The average age of a servicemen is about 25 years of age, therefore given current life expectancy rates, 40 years is a reasonable amount of years to project payment of benefits, even assuming the veteran does not claim for some years following the period of service.

6 Bilmes, Linda and Stiglitz, Joseph, The Economic Costs of the Iraq War: An Appraisal Three Years After the Beginning of the Conflict, NBER Working Paper 12054 (http://www.nber.org/papers/w12054), February 2006. The long-term budgetary costs associated with veterans health and disability cited in that paper ranged from $\$ 77 \mathrm{bn}$ to $\$ 179 \mathrm{bn}$ (depending on the length of the war), based on a population of 550,000 unique Iraqi war veterans. After we published this paper, a number of veteran's organizations including the American Legion and Veterans for America, contacted us in appreciation of our highlighting the needs of veterans. Veterans for America has particularly encouraged further research to understand the needs of the returning GWOT veteran's community.

${ }^{7}$ The Bilmes/Stiglitz cost of war paper did not include the costs of Afghanistan or other areas outside of Iraq in the GWOT. Had we included those costs, the total cost of war would have increased by $15-20 \%$.

${ }^{8}$ As of 9/30/06, some 421,206 (30\%) of 1,406,281 unique service members had been deployed twice or more to the wars in Iraq and Afghanistan. Army Times, December 11, 2006, page 14, from the Department of Defense, Defense Manpower Data Center, "Contingency Tracking System."

${ }^{9}$ As of 12/28/06, the DOD website listed 22,565 wounded in Operation Iraqi Freedom and 1084 wounded in Operating Enduring Freedom (Afghanistan). As noted previously, this is a narrower definition of injuries than the one used by the Veterans administration, which lists 50,508 non-mortal woundings as of 9/30/06. 
This paper will analyze the following aspects of the returning veterans' needs.

1. Disability compensation

2. Medical care

- Projected Cost

- Backlog of Pending Claims

- Capacity issues

- Projected Cost

- Veterans Centers

- Transitioning from the Department of Defense to VA care

3. Overall assessment of US readiness to meet its obligations to veterans

4. Recommendations

\section{Methodology}

All statistics used in this paper are from government sources, including publications of the Veterans Benefit Administration (VBA), Veterans Health Administration (VHA), and other VA offices, as well as from the Congressional Budget Office, the Government Accountability Office, the Department of Defense, and Congressional testimony. The numbers are based on the servicemen involved in Operation Iraqi Freedom (OIF) and Operation Enduring Freedom (OEF, Afghanistan) unless otherwise noted.

The cost and structural requirements for returning veterans will depend on several factors, including the number of US troops stationed in the region and how long they are deployed; the rate of claims and utilization of health resources by returning troops, and the rate of increase in disability payment and health care costs over time. The model developed allows the user to vary these assumptions and may be obtained with permission from the author's website. The current analysis has been performed under three "base" scenarios that reflect, broadly the three options now under consideration for the war.

- Low Scenario: The low scenario assumes that the US begins withdrawing troops in 2007 and that all US servicemen are home by 2010. This pattern is roughly in parallel with the recommendations of the bipartisan Baker Commission that reported to President Bush in November 2006. This scenario assumes that we will not deploy any new troops beyond the 1.4 million already participating in the war. It assumes that $44 \%$ of US troops will claim for disability payment over a period of years, with $87 \%$ of claims granted, following the same claims pattern as the first Gulf War in $1991^{10}$. The low scenario assumes that soldiers will initially receive the VA's 2005 average recurring benefit and that the annual rate of

\footnotetext{
${ }^{10}$ Using the claims patterns from Gulf War I is almost certainly too conservative because that war was much shorter and relied primarily on aerial bombardment, whereas the current wars involve long deployments and ground warfare. However it provides a baseline for the current Iraq/Afghan wars.
} 
increase will be $2.8 \%$ to reflect a cost-of-living adjustment only. (As opposed to the actual growth rate over the past 10 years which is $6.1 \%$ ). The medical usage in this scenario is based on the lowest possible uptake of medical care and a rate of increase that is below the historical rate of health care inflation. In short, this scenario shows the absolute basement level -- the lowest possible cost of providing medical care and disability benefits to soldiers returning from Iraq and Afghanistan under the most optimistic assumptions.

- Moderate Scenario: The moderate scenario is based on the current course of the war. This scenario uses the Congressional Budget Office's expected deployment figures, which would involve a gradual drawdown of troops but maintain a small US force in the region through 2015. Under this scenario, the total unique servicemen involved in the conflict will be 1.7 million, that is, 300,000 additional troops rotated in over the period of years. Nearly 20,000 new troops are regularly deployed into the two war zones each month, before any "surge" or escalation of the conflict is considered ${ }^{11}$ ( This scenario uses the first Gulf War as the basis for predicting the level of troops who will claim disability benefits, the rate of approval of the claims, and the utilization of medical resources. However a growth rate of $4.4 \%$ is projected for claims benefits, half way between the base cost-of-living adjustment and the actual growth rate of $6.1 \%$.

- High "Surge" Scenario: This scenario assumes that troop levels with surge in 2007 and that the total participation in the war over time will eventually reach 2 million unique servicemen by 2016. It also models the potential that half the veterans claim disability payments, which is a reasonable possibility given the ferocity of the conflict and the number of second and third deployments. This model also looks at the impact of growth in claims benefit payments and health care costs based on the actual growth rates over the past ten years. If the US decides to increase troops and all trends on disability and health care continue as they have in the past, this model presents the resulting cost consequences.

The costs estimated in this study are budgetary costs to the US government directly associated with the payment of disability benefits and medical treatment for returning OIF/OEF war veterans. The costs do not include the interest payments on the debt that is being incurred in borrowing money to finance the war. Future cash flows were discounted at a rate of $4.75 \%$ reflecting current long-term US borrowing rates.

\section{Disability Compensation}

There are 24 million living veterans, of whom roughly $11 \%$ receive disability benefits. Overall, in 2005 the US currently paid \$23.4 billion in annual disability entitlement pay

\footnotetext{
${ }^{11}$ Footnote: Analysis of DMDC's Contingency Tracking System shows 57,462 new first-time deployments between June 2006 and September 2006, an average 19,154 per month
} 
to veterans from previous wars, including 611,729 from the first Gulf War, 916,220 from Vietnam, 161,512 Korean War veterans, 356,190 World War II veterans and 3 veterans of World War I. ${ }^{12}$

All 1.4 million servicemen deployed in the current war effort are potentially eligible to claim some level of disability compensation from the Veterans Benefits Administration. Disability compensation is a monetary benefit paid to veterans with "service-connected disabilities" -- meaning that the disability was the result of an illness, disease or injury incurred or aggravated while the soldier was on active military service. Veterans are not required to seek employment nor are there any other conditions attached to the program. The explicit congressional intent in providing this benefit is "to compensate for a reduction in quality of life due to service-connected disability" and to "provide compensation for average impairment in earnings capacity." The principle dates back to the Bible at Exodus 21:25, which authorizes financial compensation for pain inflicted by another $^{13}$.

Disability compensation is graduated according to the degree of the veteran's disability, on a scale from 0 percent to 100 percent, in increments of $10 \%$. Annual benefits range from a low of $\$ 1304$ per year for a veteran with a $10 \%$ disability rating to about $\$ 44,000$ in annual benefits for those who are completely disabled ${ }^{14}$. The average benefit is $\$ 8890$ although this varies considerably; Vietnam veterans average about $\$ 11,670^{15}$. Additional benefits and pensions are payable to veterans with severe disabilities. Once deemed eligible, the veteran receives the compensation payment as a mandatory entitlement for the remainder of their lives, like Medicare and Social Security.

There is no statute of limitations on the amount of time a veteran can claim for most disability benefits. The majority of veteran's claims are within the first few years after returning, but some disabilities do not surface until years later. The VA is still handling hundreds of thousands of new claims from Vietnam era veterans for post-traumatic stress disorder and cancers linked to Agent Orange exposure.

The process for ascertaining whether a veteran is suffering from a disability, and determining the percentage level of a veteran's disability, is complicated and lengthy. A veteran must apply to one of the 57 regional offices of the Veterans Benefits Administration (VBA), where a claims adjudicator evaluates the veteran's serviceconnected impairments and assigns a rating for the degree to which the veteran is disabled. For veterans with multiple disabilities, the regional office combines the ratings into a single composite rating. If a veteran disagrees with the regional office's decision he or she can file an appeal to the VA's Board of Veterans Appeals. The Board makes a final decision and can grant or deny benefits or send the case back to the regional office

\footnotetext{
12 Ibid, page 33, "Benefits delivery network", RCS 20-0221

${ }^{13}$ See Veterans Benefits Administration "Annual Benefits Report” (ABR), 2005, page 17 for definition of disability compensation and see VA Disability Compensation Program, Legislative History, VA Office of Policy, Planning and Preparedness 2004 for principles behind the program.

${ }^{14}$ Ibid, page 24 , lists $\$ 1304$ for $10 \%$ and $\$ 31,611$ for $100 \%$, but those with $100 \%$ disability also receive additional payments that combined result in an annual payment of approximately $\$ 44,000$.

${ }^{15}$ Ibid, page 33.
} 
for further evaluation. Typically a veteran applies for disability in more than one category, for example, a mental health condition as well as a skin disorder. In such cases, VBA can decide to approve only part of the claim - which often results in the veteran appealing the decision. If the veteran is still dissatisfied with the Board's decision to grant service connection or the percentage rating, he or she can further appeal it to two even higher levels of decision-makers. ${ }^{16}$

Most employees at VA are themselves veterans, and are predisposed to assisting veterans obtain the maximum amount of benefits to which they are entitled. However, the process itself is long, cumbersome, inefficient and paperwork-intensive. The process for approving claims has been the subject of numerous GAO studies and investigations over the years. Even in 2000, before the current war, GAO identified longstanding problems in the claims processing area. These included large backlogs of pending claims, lengthy processing times for initial claims, high error rates in claims processing, and inconsistency across regional offices ${ }^{17}$. In a 2005 study, GAO found that the time to complete a veteran's claim varied from 99 days at the Salt Lake City regional office to 237 days at the Honolulu, Hawaii office ${ }^{18}$.

The backlog of pending claims has been growing since 1996. In 2000, VBA had a backlog of 69,000 pending initial compensation claims, of which one-third had been pending for more than six months ${ }^{19}$. Today, due in part to the surge in claims from the Iraq/Afghan wars, VBA has a backlog of 400,000 claims ${ }^{20}$. VBA now takes an average of 177 days (six months) to process an original claim, and an average of 657 days (nearly two years) to process an appeal. ${ }^{21}$ This compares unfavorably with the private sector health care/financial services industry, which processes an annual 30 billion claims in an average of 89.5 days per claim, including the time required for claims that are disputed ${ }^{22}$.

\section{Projected Demand for Benefits among OIF/OEF Veterans}

It is difficult to predict with certainty the number of veterans from the two current wars who will claim for some amount of disability. The first Gulf War provides a baseline number although the Iraq and Afghanistan war has been longer and has involved more ground warfare than the Desert Storm conflict, which relied largely on aerial bombardment and four days of intense ground combat. However, in both conflicts, a

\footnotetext{
${ }^{16}$ GAO, "Veterans Benefits Administration: problems and Challenges Facing Disability Claims Processing", GAO Testimony before the Subcommittee on Oversight and Investigations, House Committee on Veterans Affairs, May 18, 2000

17 Ibid.

18 "Veterans Benefits: Further Changes in VBA's Field Office Structure could help improve disability claims processing", GAO-06-149, December 2005

19 Ibid

${ }^{20}$ The VBA's backlog of pending claims was 399,751 as of December 9, 2006 (VBA Monday Morning Workload Report).

${ }^{21}$ The average time to process a claim is 177 days as of 9/06 and average time to process an appeal is 657 days (VA Performance and Accountability Report FY 2006).

${ }^{22}$ Bearing Point, Health Care/Financial Services industry report, September 14, 2006.
} 
number of veterans were exposed to depleted uranium that was used in anti-tank rounds fired by US M1 tanks and US A10 attack aircraft. Many disability claims from the first Gulf War stem from exposure to depleted uranium, which has been implicated in raising the risk of cancers and birth defects. Gulf War veterans also filed disability claims related to exposures to oil well fire pollution, low-levels of chemical warfare agents, experimental anthrax vaccines, and experimental anti-chemical warfare agent pills called pyridostigmine bromide, the anti-malaria pill Lariam, skin diseases, and disorders from living in the hot climate ${ }^{23}$, which are likely to be cited in the current conflict. However, the number of disability claims in the Iraq/Afghan wars is likely to be higher due to the significantly longer length of soldier's deployments, repeat deployments, and heavier exposure to urban combat.

Following the Gulf War the criteria for receiving benefits were widened by Congress based on evidence of widespread toxic exposures ${ }^{24}$. The same criteria for healthcare and benefits eligibility still apply to veterans of the Iraq and Afghanistan wars ${ }^{25}$. Forty-four percent of those veterans filed disability claims for a variety of conditions and $87 \%$ were approved $^{26}$. The US currently pays about $\$ 4$ billion annually in disability payments to veterans of Desert Storm/Desert Shield ${ }^{27}$.

Of the 1.4 million US servicemen who have so far been deployed in the Iraq/Afghan conflicts, 631,174 have been discharged as of September 30, 2006. Of those $46 \%$ are in the full-time military and 54\% are reservists and National Guardsmen. ${ }^{28}$ Therefore the total population that is potentially eligible for disability benefits is this number $(631,174)$. To date 152, 669 servicemen have applied for disability benefits and of those, 104,819 have been granted, 34,405 are pending and 13,445 have been rejected. This implies an approval rate of $88 \%$ to date. $^{29}$

We have estimated the cost of providing disability benefits to veterans under three scenarios. Under the low scenario, we expect that as in the first Gulf War, $44 \%$ of the current veterans will eventually claim disability, with an approval rate of $87 \%$. We estimate that the remaining 900,000 troops will be discharged in equal installments over the next 4 years bringing all US troops home by 2010. We expect the same percentage of these troops to claim for disabilities, with the same approval rate, within a further 5 years.

\footnotetext{
${ }^{23}$ Veterans for America, interview with Paul Sullivan, program director, 11/06.

24 "Veterans Benefits Improvement Act of 1994" (Public Law 103-446) and "Persian Gulf War Veterans Act of 1998 (PL 105-277).

${ }^{25}$ In fact, the VA does not distinguish, for the purpose of claims processing, between the end of the first Gulf War and the present conflict (38 USC Section 101(33) defines the Gulf War as starting on August 2 , 1990, and continuing until either the President or the Congress declares an end to it and 38 CFR 3.317 defines the locations of the conflict).

${ }^{26}$ For Gulf War, the total claims filed to date are 271,192, of which 205,911 have been approved, 20,382 were denied and 34,899 are still pending (GWVIS, August 2006, p.7: Granted Service Connection +Denied Service Connection +Claims Pending)

${ }^{27}$ Gulf War total annual payment $\$ 4.3$ billion (Ibid., VBA, ABR 2005 pp. 33)

${ }^{28}$ VHA, Office of Public Health and Environmental Hazards, November 2006

${ }^{29}$ VBA "Compensation and Benefit Activity among veterans deployed to the GWOT", July 20, 2006, obtained under Freedom of Information Act by the National Security Archive at George Washington University.
} 
We have assumed that on average, claims are lower than average rate, at the lower rate of new claimants from the first Gulf War of $\$ 6506^{30}$. This is probably an excessively conservative assumption because it projects the same rate of serious injuries as occurred in Gulf War I, when in fact we already know that more than the actual rate of serious injuries is much higher ${ }^{31}$.

The moderate scenario assumes that the war continues through 2014 with a total deployment of 1.7 million over the course of the war, and with gradually reduced deployment. It assumes that a slightly higher percentage of eligible veterans (50\%) make claims, which is more realistic given deployment lengths. This scenario uses the actual average VA benefit payment of $\$ 8890$. It assumes the rate of increase in benefits is $4.4 \%$, midway between the mandatory Cost of Living Adjustment and the actual ten-year growth rate of $6.1 \%$. The high scenario models the impact of a surge in forces bringing the total unique deployments to 2 million. It assumes $50 \%$ of eligible forces claim benefits and a rate of $6.1 \%$ increase, which is the actual rate over the past 10 years. It further assumes a higher rate of medical inflation (10\% vs. $8 \%$ in the low and moderate scenarios).

Table 1: Long-term Cost of Veterans Disability Benefits ${ }^{32}$

\begin{tabular}{|lrrr|}
\hline scenario & Low & Moderate & High \\
Disability & & & \\
Benefits (\$bn) & 67.63 & 109.98 & 126.76 \\
\hline
\end{tabular}

\section{Backlog of Pending Disability Claims}

The issue is not simply cost but also efficiency in providing disabled veterans with their benefits. In addition to all the problems detailed above, the Iraq and Afghan war veterans are filing claims of unusually high complexity (see table 3). To date, the backlog of pending claims from these recent war veterans is 34,000 , but the vast majority of servicemen from this conflict have not yet filed their claims. Even without the projected wave of claims, the VA has an overall backlog of 400,000, including thousands of Vietnam era claims. Including all pending claims and other paperwork, the VA's backlog has increased from 465,623 in 2004 to 525,270 in 2005 to 604,380 in $2006 .{ }^{33}$

\footnotetext{
${ }^{30}$ Ibid, ABR 2005, p33

${ }^{31}$ Of the 50,508 non-mortally wounded soldiers in OIF/OEF there are at least 10,000 serious injuries such as brain injuries, spinal and amputations, according to DOD sources. See also Wallsten and Kosec, AEIBrookings Working Paper 05-19, September 2005, estimate of 20\% serious brain injuries, $6 \%$ amputees and $24 \%$ other serious injuries.

${ }^{32}$ The figures in Table 1 represent the present value of disability benefits over 40 years for eligible veterans projected under the three scenarios described.

${ }^{33}$ VBA's "Monday Morning Report" of pending claims and other work performed at regional offices, cites: 11/25/06: 604,380; 11/26/05: 525,270; 11/27/04: 465,623.
} 
The fact that the VBA is largely sympathetic to the plight of disabled veterans should not obscure the fact that this system is already under tremendous strain. If only one fifth of the returning veterans who are eligible claim in a given year, and the total claims reaches a high of $38 \%$ effective rate $(44 \% * 88 \%$ approval rate), the number of likely claims at the VBA over the next ten years can be expected to rise from 104,819 to more than $600,000^{34}$. (See table 2).

Table 2: Projected Increase in Disability Claims (moderate scenario)

\begin{tabular}{|c|c|c|c|c|c|c|c|}
\hline & 2006 & 2007 & 2008 & 2009 & 2010 & 2011 & 2012 \\
\hline \multicolumn{8}{|l|}{ Disability Benefits } \\
\hline Discharged & & 118,758 & 118,758 & 118,758 & 118,758 & 118,758 & 118,758 \\
\hline cum & & 118,758 & 237,517 & 356,275 & 475,034 & 593,792 & 712,551 \\
\hline \multicolumn{8}{|l|}{ Eligible claimaints } \\
\hline Existing discharged non-claimants & 526,355 & 526,355 & 526,355 & 526,355 & 526,355 & 526,355 & 526,355 \\
\hline Newly discharged & - & 118,758 & 237,517 & 356,275 & 475,034 & 593,792 & 712,551 \\
\hline Total potential claimants & & 645,113 & 763,872 & 882,630 & $1,001,389$ & $1,120,147$ & $1,238,906$ \\
\hline Claim rate & $22 \%$ & $22 \%$ & $27 \%$ & $33 \%$ & $38 \%$ & $44 \%$ & $44 \%$ \\
\hline New claims & - & 140,312 & 207,678 & 287,958 & 381,154 & 487,264 & 538,924 \\
\hline Current beneficiaries & 104,819 & 104,819 & 104,819 & 104,819 & 104,819 & 104,819 & 104,819 \\
\hline Total claims (number) & 104,819 & 245,131 & 312,497 & 392,777 & 485,973 & 592,083 & 643,743 \\
\hline Total claims (\$bn) & 0.93 & 2.27 & 2.89 & 3.63 & 4.49 & 5.47 & 5.95 \\
\hline
\end{tabular}

If nothing is done to address the problem, the claims backlog will continue to grow throughout the period of the war, along with growing inequity between different regional offices. A key question is: what is a reasonable amount of time for the US to make a disabled veteran wait for a disability check? This paper proposes several actions that could reduce the length of time for processing from zero to 90 days. (Described in more detail in Section 4: Recommendations). These include: (a) greater use of the "Vet Centers" to provide assistance for veterans to file their claims, (b) automatically granting all or some of the claims, with subsequent audits to deter fraud, and (c) streamlining and technologically upgrading the claims system into a "fast track" where veterans receive a quick decision on most claims.

\section{Veterans Medical Care Shortfall}

The VA's Veterans Health Administration provides medical care to more than 5 million veterans each year. This care includes primary and secondary care, as well as dental, eye and mental health care, hospital inpatient and outpatient services. The care is free to all returning veterans for the first two years after they return from active duty; thereafter the VA imposes co-payments for various services, with the amounts related to the level of disability of the veteran ${ }^{35}$.

\footnotetext{
${ }^{34}$ This projection based on the moderate scenario described previously, based on 1.7 million unique servicemen and CBO troop deployment figures through 2014.

${ }^{35} 38$ USC Section 1710
} 
The VA has long prided itself on the excellence of care that it provides to veterans. In particular, VA hospitals and clinics are known to perform a heroic job in areas such rehabilitation. Medical staff is experienced in working with veterans and provides a sympathetic and supportive environment for those who are disabled. It is therefore of utmost important that the quality of care be maintained as the demand for it goes up.

However, the demand for VA medical treatment is far exceeding what the VA had anticipated. This has produced long waiting lists and in some cases simply the absence of care. To date, 205,097 , or $32 \%$ of the 631,174 eligible discharged OEF/OIF veterans have sought treatment at VA health facilities. These include $35 \%$ of the eligible active duty servicemen $(101,260)$ and $31 \%$ of the eligible Reservists/Guards $(103,837)$. To date, this number represents only $4 \%$ of the total patient visits at VA facilities - but it will grow. According to the VA, "As in other cohorts of military veterans, the percentage of OIF/OEF veterans receiving medical care from the VA and the percentage of veterans with any type of diagnosis will tend to increase over time as these veterans continue to enroll for VA health care and to develop new health problems" ${ }^{\text {36. }}$

The war in Iraq has been noteworthy for the types of injuries sustained by the soldiers. Some $20 \%$ have suffered brain trauma, spinal injuries or amputations; another $20 \%$ have suffered other major injuries such as amputations, blindness, partial blindness or deafness, and serious burns.

However, the largest unmet need is in the area of mental health care. The strain of extended deployments, the stop-loss policy, stressful ground warfare and uncertainty regarding discharge and leave has taken an especially high toll on soldiers. Thirty-six percent of the veterans treated so far -- an unprecedented number -- have been diagnosed with a mental health condition. These include PTSD, acute depression, substance abuse and other conditions. According to Paul Sullivan, a leading veterans advocate, "The signature wounds from the wars will be (1) traumatic brain injury, (2) post-traumatic stress disorder, (3) amputations and (4) spinal chord injuries, and PTSD will be the most controversial and most expensive" 37 (see Table 3)

Table 3: VHA Office of Public Health, November 2006

\footnotetext{
${ }^{36}$ VHA, Office of Public Health and Environmental Hazards, November 2006, Ibid, p. 14

${ }^{37}$ Paul Sullivan, Program Director of Veterans for America, 12/23/06 interview
} 


\title{
Frequency of Possible Diagnoses Among Recent Iraq and Afghan Veterans
}

\author{
Diagnosis \\ (Broad ICD-9 Categories) \\ Infectious and Parasitic Diseases (001-139) \\ Malignant Neoplasms (140-208) \\ Benign Neoplasms (210-239) \\ Diseases of Endocrine/Nutritional/ Metabolic Systems (240-279) \\ Diseases of Blood and Blood Forming Organs (280-289) \\ Mental Disorders (290-319) \\ Diseases of Nervous System/ Sense Organs (320-389) \\ Diseases of Circulatory System (390-459) \\ Disease of Respiratory System (460-519) \\ Disease of Digestive System (520-579) \\ Diseases of Genitourinary System (580-629) \\ Diseases of Skin (680-709) \\ Diseases of Musculoskeletal System/Connective System (710-739) \\ Symptoms, Signs and III Defined Conditions (780-799) \\ Injury/Poisonings (800-999)
}

\begin{tabular}{rr}
\multicolumn{2}{c}{$(\mathbf{n}=\mathbf{2 0 5 , 0 9 7 )}$} \\
Frequency ${ }^{*}$ & $\%$ \\
& \\
21,362 & 10.4 \\
1,584 & 0.8 \\
6,571 & 3.2 \\
36,409 & 17.8 \\
3,591 & 1.8 \\
73,157 & 35.7 \\
61,524 & 30.0 \\
29,249 & 14.3 \\
36,190 & 17.6 \\
63,002 & 30.7 \\
18,886 & 9.2 \\
29,010 & 14.1 \\
87,590 & 42.7 \\
67,743 & 33.0 \\
35,765 & 17.4
\end{tabular}

*Hospitalizations and outpatient visits as of 9/30/2006; veterans can have multiple diagnoses with each healthcare encounter. A veteran is counted only once in any single diagnostic category but can be counted in multiple categories, so the above numbers add up to greater than 205,097 .

Additionally, far more returning Iraqi war veterans (than those in previous conflicts) are likely to seek such help, in part due to awareness campaigns run by veteran's organizations through the press. There is no reliable data on the length of waiting lists for returning veterans, but even the VA concedes that they are so long as to effectively deny treatment to a number of veterans. In the May 2006 edition of Psychiatric News, Frances Murphy M.D., the Under Secretary for Health Policy Coordination at VA, said that mental health and substance abuse care are simply not accessible at some VA facilities. When the services are available, Dr. Murphy asserted that, "waiting lists render that care virtually inaccessible.",38

The VA curiously maintains that it can cope with the surge in demand, despite much evidence to the contrary. For the past two years, the VA ran out of money to provide health care. In FY 2006, the VA was obliged to submit an emergency supplemental budget request for $\$ 2$ billion, which included $\$ 677$ million to cover an unexpected $2 \%$ increase in the number of patients (half of which were OIF/OEF patients), $\$ 600$ million to correct its inaccurate estimate of long-term care costs, and $\$ 400$ million to cover an unexpected $1.2 \%$ increase in the costs per patient due to medical inflation. The previous year, (FY 2005), VA requested an additional \$1 billion, of which one-quarter was for unexpected OIF/OEF needs and remainder was related to overall under-estimation of patient costs, workload, waiting lists, and dependent care. The GAO analysis of these shortfalls concluded that they were due to the fact that VA was modeling its projections based on 2002 data, before the war in Iraq began ${ }^{39}$.

\footnotetext{
${ }^{38}$ Frances Murphy, May 2006, Psychiatric News

${ }^{39}$ GAO-06-430R, "VA Health Care Budget Formulation”, pp 18-20.
} 
The budget shortfalls and the statement by Dr. Murphy suggest that the volume of veterans returning from Iraq and Afghanistan will not be able to obtain the health care they need, particularly for mental health conditions. Such veterans are at high risk for unemployment, homelessness, family violence, crime, alcoholism, and drug abuse, all of which impose an additional human and financial burden on the nation. In addition, many of these social services are provided by state and local governments which are already under tremendous strain.

\section{Projected Medical Costs}

The number of veterans who will eventually require treatment can be estimated using a baseline of the utilization during the first Gulf War, in which the VA is providing medical care to $48 \%$ of veterans. The average annual cost of treating veterans in the system is now $\$ 5000^{40}$, although it is difficult to know whether the more grievous injuries and disabilities of the current conflict will drive up costs per patient.

The costs of providing medical care have been calculated under the three scenarios. Under the low scenario, under which the US will deploy no new troops, the ceiling for medical care is $48 \%$ of OIF/OEF veterans. If half of all veterans eventually seek medical treatment from the VA that will produce a demand of some 700,000 veterans. However, due to the fact that veterans are eligible for free care during the first two years after discharge, we can expect a wave of returning war veterans within two years of their discharge date. Additionally, since active duty veterans claim medical care at a higher rate (than Guards/Reservists) and have been deployed in more of the most hazardous front-line task come home, we can expect that the average cost of treating such veterans increases as well as a high level of demand ${ }^{41}$.

If the demand for medical care increases as projected to some 700,000 or more veterans, there is a serious risk that the VA, which is already overwhelmed, will be unable to meet the medical needs of returning OIF/OEF veterans. Additional staff is needed in important areas such as brain trauma units and mental health. The VA also needs to expand systems such as triage nursing, to help leverage scarce medical resources.

Even assuming that no more troops are deployed, the long-term cost of treating returning veterans will reach $\$ 208$ billion. This however assumes that the supply of health care exists to treat them. If the number of troops continues to grow as in the moderate then cost of providing lifetime care rises to $\$ 315$ billion. The annual budget payment under this scenario will reach $\$ 3$ bn by 2010 and more than double by 2014. (See Table 4)

\footnotetext{
${ }^{40}$ This amount is calculated by estimating the budget 2006 supplemental budget request for OIF/OEF veterans per additional patient, using the GAO analysis in GAO-06-430R

${ }^{41}$ VHA, Office of Public Health and Environmental Hazards, Ibid.
} 
Table 4: Projected Cost of for Providing VA Medical Care (moderate scenario) ${ }^{42}$

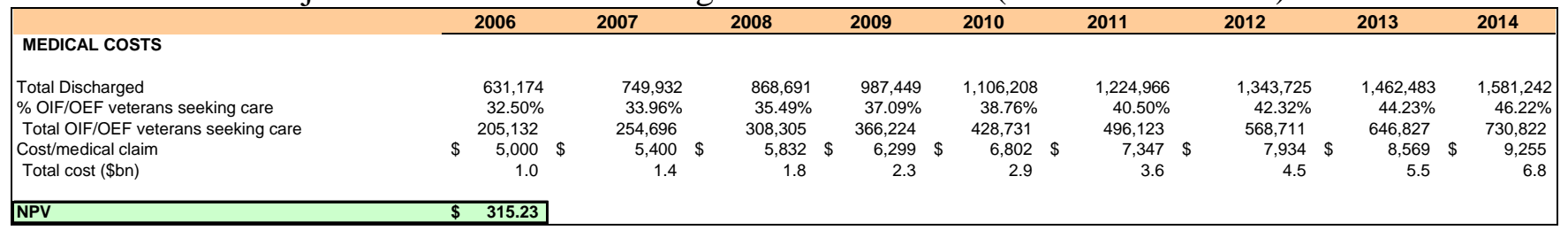

However, these scenarios are conservative in assuming that only half of the returning veterans will eventually seek medical treatment from the VA and that the level of health care inflation will remain constant at $8 \%$. Under a worst-case scenario, if troops levels rise to 2 million and if health inflation rises to the double-digit levels experienced during the 1990 s, we can expect the total cost of providing lifetime medical care to veterans to reach $\$ 600 \mathrm{bn}^{43}$.

\section{$\underline{\text { Veterans Centers }}$}

How can the VA possibly handle the number of returning troops who require care, as well as their families, especially for mental health conditions? Perhaps the most creative and successful innovation in the VA in past two decades has been the introduction of the "Vet Centers" -- 207 walk-in storefront centers where veterans or their families can obtain counseling and reintegration assistance. The centers, operated by VA's "Readjustment Counseling Service" are popular with veterans and their families and - at a total cost of some $\$ 100 \mathrm{~m}$ per year -- provide a highly cost-effective option for veterans who are not in need of acute medical care. The Vet Centers are particularly helpful for families, for example they provide a venue for a soldier's spouse to seek guidance of the veteran is showing mental distress but will not seek help. They also supply bereavement counseling to surviving families of those killed during military service. And they offer a friendlier environment often staffed with recent OEF/OIF combat veterans and other war veterans - unlike VA regional offices which tend to be stuffy, bureaucratic offices located in downtown locations ${ }^{44}$.

To date, 144,000 veterans have sought assistance at these centers ${ }^{45}$. However the demand for their services is threatening their ability to provide care. Vet Center managers recently surveyed by Congress said that in $50 \%$ of the Centers, the increasing workload is affecting their ability to treat veterans. Some $40 \%$ of the Vet Centers have directed veterans for whom individualized therapy would be appropriate into group therapy, and more than one-quarter of the Centers have limited or plan to limit family therapy. Nearly $17 \%$ have established waiting lists (or are in the process of setting them up) ${ }^{46}$.

\footnotetext{
${ }^{42}$ The NPV is calculated over 40 years, at a discount rate of $4.75 \%$, with a peak rate of $50 \%$ veterans claiming care by 2016.

${ }^{43}$ High scenario assuming $10 \%$ medical inflation rate.

${ }^{44}$ Opinion based on conversations with veterans organizations.

${ }^{45}$ Vet Center costs document, page 3B-11

${ }^{46}$ October 2006 report issued by the House Veterans Affairs Committee, testimony by Vet Center managers.
} 
Currently the centers do not assist veterans in filing disability claims, but provided that the facility had sufficient secure storage space to handle such documents, there is no reason why they could not. The VA has recommended hiring an additional 1000 claims adjudicators - who could be placed in the Vet Centers (an average of 5 each) to help veterans figure out how to claim. The cost of expanding the number of centers, hiring additional staff and placing more claims adjudicators in the centers is minimal.

\section{Transition from DOD Payroll to VA Care}

One of the chief bottlenecks in the current system is the soldier's transition from the DOD payroll into the VA benefit system. There are three primary ways that a soldier makes this transition.

A veteran who is discharged regularly, and has some level of disability will typically have to wait 6 months before receiving his or her disability check from the VA. This is a period during which the veterans, particularly those in a state of mental distress, are most at risk for serious problems, including suicide, falling into substance abuse, divorce, losing their job, or becoming homeless.

A second route is to exit via the "Benefits Delivery at Discharge" (BDD) program. This successful program allows soldiers to process their claims up to six months prior to discharge, so they can begin receiving benefits as soon as they leave the military. However, the use of this route has become much more difficult due to the extended deployments, the use of "stop-loss" orders, and the resulting unpredictability about when a soldier will be discharged. Additionally, this program is not available to Reservists and Guardsmen, who comprise $40 \%$ of the forces in Iraq and Afghanistan. The VBA claim denial rate is twice as high for Reserve and Guard veterans, possibly due in part to their lack of access to BDD. ${ }^{47}$ Consequently the usage of this apparently better route has not been increasing as would have been expected. ${ }^{48}$.

For veterans who are more seriously wounded, the process is more complicated as they transition from medical facilities run by DOD into medical facilities run by the VA. For example a wounded veteran may be treated initially at Walter Reed Army Hospital and then transferred to a VA facility. Veterans experience some difficulties is securing the maximum amount of disability benefits at discharge during such transitions, due to a lack of compatibility between the DOD and VA paperwork and tracking systems. The VA complains that the records they receive from DOD are delayed or contain errors, in many cases it is the situation where the data that is tracked is not compatible. This not only creates unnecessary problems in moving veterans through the system but it also makes it more difficult for the data to be analyzed in medical and other studies.

\footnotetext{
${ }^{47}$ Active Duty denial rate is 7.6 percent compared with National Guard and Reserve denial rate of 17.8 percent, See Footnote 28

${ }^{48}$ Congressional testimony of Jack McCoy, VBA, March 16, 2006, http://www.va.gov/OCA/testimony/hvac/sdama/060316JM.asp and a VA fact sheet indicate 26,000 BDD claims in 2003, 39,000 in 2004, and 46,000 in 2005. http://www1.va.gov/opa/fact/tranasst.asp
} 
Additionally there are the problems caused by the Pentagon's poor accounting system. GAO investigators have found that DOD pursued hundreds of battle-injured soldiers for payment of non-existent military debts - because DOD financial systems erroneously reported that they were indebted. For example, one Army Reserve Staff Sergeant, who lost his right leg below the knee, was forced to spend 18 months disputing an erroneously recorded debt of $\$ 2231$ which prevented him from obtaining a mortgage to purchase a home. Another staff sergeant who suffered massive brain damage and PTSD had his pay stopped and utilities turned off because the military erroneously recorded a debt of $\$ 12,000$. Hundreds of injured soldiers may be in this situation ${ }^{49}$.

\section{$\underline{\text { Overall Assessment and Cost }}$}

Overall the US is not adequately prepared for the influx of returning servicemen from Iraq and Afghanistan. There are three major areas in which it is not prepared: claims processing capacity for disability benefits; medical treatment capacity, in terms of the number of health care personnel available at clinics throughout the country, particularly in mental health; and third, there is no preparation for paying the cost of another major entitlement program.

As discussed earlier, the backlog in claims benefit is already somewhere between 400,000 and 600,000. Unless major changes are made to this process, the number of claims pending and requiring attention will reach some 750,000 within the next two years and the pendency period will increase proportionately, resulting in more veterans falling though the cracks that could have been avoided. In addition, veterans whose claims reach different centers in different parts of the country will have widely different experiences, proving highly unfair to those who just happen to be located in areas of greater backlog.

The quality of medical care is likely to continue to be high for veterans with serious injuries treated in VA's new polytrauma centers. However, the current supply of care makes it unlikely that all facilities can offer veterans a high quality of care in a timely fashion. Veterans with mental health conditions are most likely to be at risk because of the lack of manpower and the inability of those scheduling appointments to distinguish between higher and lower risk conditions. If the current trends continue, the VA is likely to see demand for health care rising to 750,000 veterans in the next few years, which will overwhelm the system in terms of scheduling, diagnostic testing, and visiting specialists, especially in some regions ${ }^{50}$.

The cost of providing disability benefits and medical care, even under the most optimistic scenario that no additional troops are deployed and the claims pattern is only that of the previous Gulf War, would suggest that at a minimum the cost of providing lifetime disability benefits and medical care is $\$ 350$ billion. If the number of unique troops increases by another 200,000 to 500,000 over a period of years, this number may rise to

\footnotetext{
${ }^{49}$ GAO-06-494, "Hundred of Battle-Injured GWOT Soldiers Have Struggled to Resolve Military Debts"

${ }^{50}$ However, the availability of medical care may vary significantly by region.
} 
as high as nearly $\$ 700 \mathrm{bn}$. (See Table 5) The funding needs for veterans' benefits thus comprise an additional major entitlement program along with Medicare and Social Security that will need to be financed through borrowing if the US remains in deficit. This will in turn place further pressure on all discretionary spending including that for additional veterans' medical care.

Table 5: Total Veterans Disability and Medical Costs ${ }^{51}$

\begin{tabular}{|l|r|c|c|}
\hline & LOW & MODERATE & HIGH \\
\hline Disability & 67.6 & 109.5 & 126.8 \\
\hline Medical & 282.2 & 315.2 & 536.0 \\
\hline TOTAL $(\$ B n)$ & 349.8 & 424.7 & 662.8 \\
\hline
\end{tabular}

In the context of the overall costs of the War

Veteran's disability benefits and medical care are two of the most significant long-term costs of the War. As shown in our previous analysis of the costs of the war, the war has both budgetary and economic costs. This paper focuses only on the budgetary costs of caring for veterans. It does not take into account the value of lives lost, or effectively lost due to grievous injury. Not does it take into account the economic impact of the large number of veterans living with disabilities who cannot engage in full economic activities $^{52}$.

\footnotetext{
${ }^{51}$ Total lifetime costs over 40 years, discounted at $4.75 \%$ under scenarios described.

52 This paper considers only the budgetary costs of veterans care. Standard economic theory would treat disability benefits as a transfer payment and deduct these from the economic and social loss associated with veteran's reduced economic lives. This was the methodology used in (stiglitz paper).
} 


\section{$\underline{\text { Recommendations }}$}

\section{a) Medical Care}

The Veterans Health Administration will not be able sustain its high quality of care without greater funding and increased capacity in areas such as psychiatric care and brain trauma units. In addition, more funding should be provided for readjustment counseling services by social workers at the Vet Centers. Even doubling the amount of funding for counseling at the Vet Centers is a small amount compared to the funds now being requested for additional recruiting of new soldiers.

\section{(b) Disability Claims Backlog}

There are at least three potential methods of reducing the number of pending claims. Perhaps the easiest would be to "fast track" returning Iraq and Afghan war veteran's claims in a single center staffed with highly experienced group of adjudicators who could provide most veterans with a decision within 90 days. At a minimum, all simple claims could be dispatched in this manner. During the past decade, private sector health insurance companies have reengineered their processes and adopted technologies, such as new automated data capture and document processing systems that have dramatically improved their ability to handle large volumes of information. This has allowed the industry to bring the average claim processing time down to 89.5 days. For example, the firm Noridian used technology to enable operators to process four to five times more claims in the same amount of time as under their old system, and to speed the form retrieval process for better customer service ${ }^{53}$.

The VA has proposed a more typically governmental solution of adding 1000 more claims adjudicators. Even apart from the cost of $\$ 80 \mathrm{~m}$ or so of adding these personnel, the question is whether adding additional personnel to a cumbersome system is the best possible way to speed up transactions and improve service. A better idea would be to expand the Vet Centers to offer some assistance in helping veterans figure out their disability claims. The 1000 claims experts could be placed inside the Vet Centers (5 per center), thus enabling veterans and their families to obtain quick assistance for many routine claims. Vet Centers would only require minor modifications (secure storage space, additional computers and offices) to fill this role.

The best solution might be to simplify the process -- by adopting something closer to the way the IRS deals with tax returns. The VBA could simply approve all veterans' claims as they are filed - at least to a certain minimum level -- and then audit a sample of them to weed out and deter fraudulent claims. At present, nearly 90 percent of claims are approved. VBA claims specialists could then be redeployed to assist veterans in making claims, especially at VA's "Vet Centers." This startlingly easy switch would ensure that the US no longer leaves disabled veterans to fend for themselves.

${ }^{53}$ KM World, June 1999. 
The cost of any solution that reduced the backlog of claims is likely to be an increased number of claims, and a quicker pay-out. If $88 \%$ of claims were paid within 90 days instead of the 6 months to 2 years currently required, the additional budgetary cost is likely to be in the range of $\$ 500 \mathrm{~m}$ in 2007 .

\section{$\underline{\text { Conclusions }}$}

President Bush is now asking for more money to spend on recruiting in order to boost the size of the Army and deploy more troops to Iraq. But what about taking care of those same soldiers when they return home as veterans? The number of veterans who are returning home with injuries or disabilities is large and growing. We have not paid careful enough attention, or devoted sufficient resources, to planning for how to take care of these men and women who have served the nation.

There has been a tendency in the media to focus on the number of US deaths in Iraq, rather than the volume of wounded, injured, or sick. . This may have led the public to underestimate the deadliness and long-term impact of the war on civilian society and the government's pocketbook. Were it not for modern medical advances and better body armor, we would have suffered even more loss of life.

One of the first votes facing the new Democratic-controlled Congress will be yet another "supplemental" budget request for $\$ 100+$ billion to keep the war going. The last Congress approved a dozen such requests with barely a peep, afraid of "not supporting our troops". If the new Congress really wants to support our troops, it should start by spending a few more pennies on the ones who have already fought and come home.

\section{Limitations of Data}

This paper has been prepared based on the best available data from VA sources, CBO, $\mathrm{GAO}$, and veterans organizations. Reconciling this data has therefore been done to try to generate realistic estimates, but is not precise. It is also difficult to predict with certainty the uptake in the military of benefits and medical care. In all cases this study has been done conservatively, for example it is entirely possible that after the length and grueling nature of this war, that a much higher number - perhaps $2 / 3$ of returning veterans would seek disability benefits and/or healthcare and the estimates in this paper prove too low.

\section{$\underline{\text { Issues not addressed }}$}

This paper has not attempted to address the cost of taking care of wounded and disabled Iraqi soldiers in Iraq. A number of studies have estimated the fatalities in Iraq, but there are few studies of the number of injuries among the Iraqi military. As the US continues to place an emphasis on developing the Iraqi military to replace it, it is worth asking what the cost to that country will be of providing medical care and any kind of long-term 
benefits to those who are fighting. This study excludes VBA benefits such as education, insurance, vocational rehabilitation, and home loan guaranty programs. This study also excludes private, state, and local healthcare, disability, and employment benefits for returning veterans.

\section{Acknowledgements}

This paper was prepared with the invaluable assistance of Tony Park, a student at the Kennedy School of Government, and Paul Sullivan, Director of Research and Analysis at Veterans for America. Their contributions are gratefully acknowledged. 